\title{
Doppler Study of Uterine and Ovarian Arteries in Cases of Unexplained Infertility (Case Control Study)
}

\author{
MOHAMED E. ALI, M.D.*; HEBA A. ELSWAH, M.D.*; AYMAN A. HASSAN. M.D.*; \\ YASSMIN T. EL-SHEWEY, M.D.** and DALIA A. NOUR, M.Sc.* \\ The Departments of Obstetrics \& Gynecology* and Chemical Pathology**, Faculty of Medicine, Cairo University
}

\begin{abstract}
Background: Infertility defined as failure to conceive after 12 months of unprotected regular intercourse. Unexplained infertility describes couples with infertility in whom standard investigations including semen analysis, tests of ovulation, and tubal patency have no gross abnormality.

Aim of Study: Mid-luteal phase resistant index (RI) and pulsatlity index (PI) of uterine and ovarian arteries evaluation in unexplained infertility patients and compare those parameters with fertile controls in order to reveal the possible role of the uterine perfusion abnormality in unexplained infertility.

Patients \&Methods: In this study, we included 100 participants presented to the outpatient clinic in Kasr El-Aini maternity hospital, they were classified into two groups: Group A: 50 participants presented with unexplained infertility either primary or secondary (the case group). Group B: 50 participants who had no history of infertility and multipara who came for any gynecological procedure (the control group) Primary outcome measures resistant index (RI) and pulsitility index (PI) of both uterine and ovarian arteries in mid luteal phase after measurement of serum progesterone level in both groups.
\end{abstract}

Results: The uterine artery (RI) is higher in case group $(0.86 \pm 0.06)(0.85 \pm 0.07)$ than in control group $(0.77 \pm 0.04)$. The ovarian artery $(\mathrm{RI})$ is higher in case group $(0.66 \pm 0.03)$ $(0.65 \pm 0.08)$ than in control group $(0.63 \pm 0.02)$. The uterine artery $(\mathrm{PI})$ is higher in case group $(2.17 \pm 0.22)(2.14 \pm 0.16)$ than in control group $(1.80 \pm 0.10)(1.80 \pm 0.15)$ and the ovarian artery (PI) is higher in case group $(1.97 \pm 0.13)(1.97 \pm 0.12)$ than in control group $(1.54 \pm 0.17)(1.56 \pm 0.17)$ which all statistically significant. As regards to serum progesterone level it was higher in control group $(12.87 \pm 2.47)$ than in case group $(12.66 \pm 3.17)$ which was statistically insignificant.

Conclusion: From our study we found that uterine perfusion impairment could be of value in cases of unexplained infertility.

Key Words: Unexplained Infertility - Uterine artery Doppler - Ovarian Artery Doppler.

Correspondence to: Dr. Mohamed E. Ali, The Department of Obstetrics \& Gynecology, Faculty of Medicine,

Cairo University

\section{Introduction}

INFERTILITY defined as failure to conceive after 12 months of unprotected regular intercourse. It affects $17 \%$ of the couples, with $40 \%$ of the cases cased by female pathology [1].

Infertility can be primary, in women who have never conceived, or secondary, in women have previously conceived. This review will deal with infertility due to unexplained infertility. It represents $10 \%$ to $20 \%$ of infertility cases [2]

Unexplained infertility describes couples with infertility in whom standard investigations including semen analysis, tests of ovulation, and tubal patency have no gross abnormality [3]

Endometrial receptivity under control of many factors including uterine perfusion [4].

Several studies have shown that uterine receptivity is decreased when the uterine artery impedance has been increased during the mid luteal phase [5].

Abnormal uterine perfusion may be a contributing factor of infertility especially in couples with unexplained infertility. Pulsed Doppler is an important tool for examining the female genital system. It is a non-invasive method to assess the uterine perfusion [6].

Transvaginal ultrasonography with colour Doppler imaging and pulsed Doppler spectral analysis have been used to measure resistant index (RI) and pulstility index (PI) of uterine and ovarian arteries.

The aim of this study is to evaluate the midluteal phase resistant index (RI) and pulsitility 
index (PI) of uterine and ovarian arteries in unexplained infertility patients and compare those parameters with fertile controls in order to reveal the possible role of the uterine perfusion in the infertility.

\section{Patients and Methods}

We performed the study during the period from (June 2013) till (2015) we had 100 participants presented to the Outpatient Clinic in Kasr El-Aini Maternity Hospital; they were classified into two groups:

- Group A: 50 participants diagnosed as unexplained infertility either primary or secondary (the case group).

- Group B: 50 participants who had no history of infertility and came for any gynecological procedure (the control group).

At the time of initial recruitment, the purpose of the study was adequately explained to each participant. Consent is taken. History was taken and serum progesterone level was sampled at mid luteal phase then transvaginal power Doppler ultrasonography was performed to all patients in luteal phase (day 21-22) of cycle to detect uterine artery resistant index (UARI), pulsatility index (UAPI) and ovarian artery resistant index (OARI), pulsitility index (OAPI).

\section{Inclusion criteria for the infertility group:}

- Age between 18-40 years old.

- Infertility either primary or secondary.

- Investigations were done:

- Semen analysis to exclude male factor.

- Hormonal profile (FSH, LH, E2 \& prolactin).

- HSG revealed no congenital anomalies, masses, or adhesions within the uterine cavity and patent fallopian tubes, and transvaginal ultrasonography revealed adequate secretory endometrium within the luteal phase.

Inclusion criteria for the control group:

- Age between 18-40 years old.

- Multiparous women in mid luteal phase.

- No hormonal contraception.

- Norma serum progesterone in midluteal phase.

Exclusion criteria for both groups:

- Infertility due to ovarian factor.

- Infertility due to tubal disease.

- Infertility due to uterine or cervical cause.
- Infertility due to male factor.

- Pregnant woman.

- Patient who refuse to participate in the study.

Steps \& Methods:

Patients to be recruited gave an informed consent and were subjected to:

1 - Complete history taking: Which include:

- Personal history

- Menstrual history

- Obstetric history

- Past history

2- General, abdominal and pelvic examination:

- General examination:

- General examination: Signs of thyroid disease.

- Breast examination for swelling or nipple discharge.

- Abdominal examination.

- Pelvic examination.

3- Investigations: (infertility group):

- Semen analysis to exclude male factor of infertility.

- Hormonal profile at 3 rd day of the cycle (FSH, LH, Estrogen and prolactin).

- HSG to confirm the patency of the fallopian tubes, and to exclude any structural abnormality of the uterus.

- Serum progesterone level at 21 st - 22nd day of the cycle:

- The sample is collected from patient.

- Centrifugation is done to obtain at least 1-ml of serum.

- Serum progesterone level is a radioimmunoassay performed with in-house reagents. The radioimmuno-assay technique is based on the competitive binding of the serum progesterone and a radio labeled progesterone preparation. They compete for binding to an antibody specific for progesterone. The antibody-bound radio labeled progesterone is separated and the quantity is determined by counting in a gamma spectrometer. Results for the unknown are read from a curve prepared by plotting results for a set of known standards. Sera with pre-determined concentrations are included in every extraction procedure and assayed for quality control purposes). 
4- Type of ultrasound: All examinations were performed with the scanner (Voluson 730 PRO) with $7.5 \mathrm{MHZ}$ endocavitary transducer with pulsed colour Doppler and 3D facility.

\section{Technique of transvaginal ultrasound:}

1- Preparation of the patient for ultrasound examination.

2- The examination table: For the scanning procedure an in-line transducer probe (a probe that has an end firing scan head with its shaft and handle on the same axis), so a flat ultrasound examination table was appropriate. The elevated thighs enabled free movement of the probe in the horizontal plane by the operator.

\section{3- The equipment and the transducer: All the} patients were subjected to the following:

The vaginal probe was covered with a condom containing a small amount of gel. The gel ensured good contact between the transducer and the overlying condom. Care was taken to avoid trapping of any air bubbles, which might have created unwanted artifacts on the screen. Cross infection was prevented by the use of probe cover and disinfectants.

Transvaginal probe will be inserted into the vagina and placed in the anterior fornix, and the internal and external cervical os are identified, and uterine examination will be performed to rule out any uterine anomaly that might interfere with pregnancy such as uterine septum, bicornuate uterus, and uterine myomas and to rule out any abnormalities in the secretory endometrium.

The probe will be then moved laterally and the right uterine artery will be identified, using color Doppler, as an aliasing vessel running along the side of the cervix at the level of the internal os, then the left one will be identified by the same way.

Pulsed wave Doppler will be used to obtain clear, consistent, flow velocity wave forms of both uterine arteries. Resistant index (RI) and Pulsitility index (PI) will be measured bilaterally.

The probe will be moved 90 degree to have transverse section in the uterus then moved laterally to get the right ovarian artery in the ovarian fossa which will be identified, using color Doppler, then the left one will be identified by the same way.

Pulsed wave Doppler will be used to obtain clear, consistent, flow velocity wave forms of both ovarian arteries. Resistant index (RI) and pulsitility index (PI) will be measured bilaterally.

\section{Statistically analysis:}

Quantitative variables are expressed as mean \pm standard deviation $( \pm$ S.D $)$ and comparisons were performed using the $t$-test for independent samples if the samples were normally distributed or by the Mann-Whitney test otherwise. The significance level was 0.05 and $p$-values less than 0.05 were considered significant. Binary logistic regression analysis model has been performed to predict a categorical variable from a set of predictor variables.

Data were statistically described in terms of mean \pm standard deviation ( \pm S.D $)$, median and range, or frequencies (number of cases) and percentages when appropriate. Comparison of numerical variables between the study groups was done using Student $t$-test for independent sampleş. For comparing categorical data, Chi square $(\chi)$ test was performed. Exact test was used instead when the expected frequency is less than 5. $p$-values less than 0.05 was considered statistically significant. All statistical calculations were done using computer program SPSS (Statistical Package for the Social Science; SPSS Inc., Chicago, IL, USA) release 15 for Microsoft Windows.

\section{Results}

The age in control group (27.72 \pm 5.86$)$ was higher than case group $(26.56 \pm 5.32)$ but with no statistical significance ( $p$-value 0.302 ). Gravidity was higher in control group $(2.30 \pm 1.22)$ than in case group $(1.22 \pm 1.40)$ which was statistically significant, ( $p$-value 0.001). Parity was higher in control group (2.04 \pm 1.14$)$ than in case group $(0.92 \pm 1.26)$ which was statistically significant, $(p$ value 0.001 ).

The uterine artery (RI) is higher in case group $(0.86 \pm 0.06)(0.85 \pm 0.07)$ than in control group $(0.77 \pm 0.04)$ which was statistically significant $(p$ value 0.001$)$. The ovarian artery (RI) is higher in case group $(0.66 \pm 0.03)(0.65 \pm 0.08)$ than in control group $(0.63 \pm 0.02)$ which was statistically significant ( $p$-value 0.001$)$. The uterine artery (PI) is higher in case group $(2.17 \pm 0.22)(2.14 \pm 0.16)$ than in control group $(1.80 \pm 0.10)(1.80 \pm 0.15)$ which was statistically significant, ( $p$-value 0.001$)$. The ovarian artery (PI) is higher in case group $(1.97 \pm 0.13)(1.97 \pm 0.12)$ than in control group $(1.54 \pm 0.17)(1.56 \pm 0.17)$ which was statistically significant ( $p$-value 0.001).

As regards to serum progesterone level it was higher in control group $(12.87 \pm 2.47)$ than in case group $(12.66 \pm 3.17)$ which was statistically insignificant ( $p$-value 0.718$)$. 
Table (1): Comparison in age, gravidity and parity between case and control group.

\begin{tabular}{lccl}
\hline & $\begin{array}{c}\text { Control group } \\
(\mathrm{n}=50)\end{array}$ & $\begin{array}{c}\text { Case group } \\
(\mathrm{n}=50)\end{array}$ & $p$-value \\
\hline $\begin{array}{c}\text { Age: } \\
\text { Mean } \pm \text { S.D }\end{array}$ & $27.72 \pm 5.86$ & $26.56 \pm 5.32$ & $0.302(\mathrm{NS})$ \\
$\begin{array}{c}\text { Gravidity: } \\
\text { Mean } \pm \text { S.D }\end{array}$ & $2.30 \pm 1.22$ & $1.22 \pm 1.40$ & 0.001 \\
$\begin{array}{c}\text { Parity: } \\
\text { Mean } \pm \text { S.D }\end{array}$ & $2.04 \pm 1.14$ & $0.92 \pm 1.26$ & 0.001 \\
\hline
\end{tabular}

Table (2): Comparison of CS incidence between the case and control group.

\begin{tabular}{cccc}
\hline & Control $(\mathrm{n}=50)$ & Cases $(\mathrm{n}=50)$ & $p$-value \\
\hline 0 & $30(60 \%)$ & $37(74 \%)$ & $0.137(\mathrm{NS})$ \\
1 & $20(40 \%)$ & $13(26 \%)$ & \\
\hline
\end{tabular}

Table (3): Type of infertility in infertility group (primary or secondary).

\begin{tabular}{lcc}
\hline & Number & Percent (\%) \\
\hline Primary & 23 & 46 \\
Secondary & 27 & 54 \\
\hline
\end{tabular}

Table (4): Comparison between mean values of uterine and ovarian (RI \& PI) in control group and case group.

\begin{tabular}{lccc}
\hline & Control $(\mathrm{n}=50)$ & Cases $(\mathrm{n}=50)$ & $p$-value \\
\hline Rt uterine: & & & \\
$\quad$ RI & $0.77 \pm 0.04$ & $0.86 \pm 0.06$ & 0.001 \\
$\quad$ PI & $1.80 \pm 0.10$ & $2.17 \pm 0.22$ & 0.001 \\
Lt uterine: & & & \\
$\quad$ RI & $0.77 \pm 0.04$ & $0.85 \pm 0.07$ & 0.001 \\
$\quad$ PI & $1.80 \pm 0.15$ & $2.14 \pm 0.16$ & 0.001 \\
$\quad$ Rt ovarian: & & & \\
$\quad$ RI & $0.63 \pm 0.02$ & $0.66 \pm 0.03$ & 0.001 \\
$\quad$ PI & $1.54 \pm 0.17$ & $1.97 \pm 0.13$ & 0.001 \\
$\quad$ Lt ovarian: & & & \\
$\quad$ RI & $0.63 \pm 0.02$ & $0.65 \pm 0.08$ & 0.041 \\
$\quad$ PI & $1.56 \pm 0.17$ & $1.97 \pm 0.12$ & 0.001 \\
\hline
\end{tabular}

Table (5): Comparison in serum progesterone level between case and control group.

\begin{tabular}{cccc}
\hline & $\begin{array}{c}\text { Control } \\
(\mathrm{n}=50)\end{array}$ & $\begin{array}{c}\text { Cases } \\
(\mathrm{n}=50)\end{array}$ & $p$-value \\
\hline Serum progesterone & $12.87 \pm 2.47$ & $12.66 \pm 3.17$ & $0.718(\mathrm{NS})$ \\
\hline
\end{tabular}

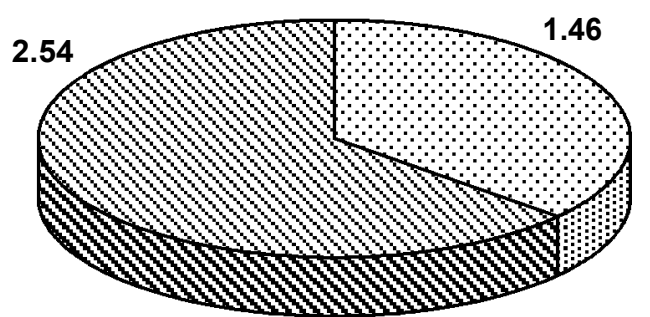

Fig. (1): Type of infertility in infertility group (primary or secondary).

\section{Discussion}

The main objective of this study was to determine whether women with unexplained infertility had a higher uterine blood flow impedance than women who had at least one live child and no history of infertility.

Battaglia $\mathrm{C}$ et al., [7] reported the highest pregnancy rate in the group with lower resistance to blood flow in the uterine spiral arteries. This finding revealing the decrease in peripheral impedance in the uterine vasculature reflected by a low uterine artery PI was considered to be a consequence of increased blood flow and a sign of high tissue perfusion, and this might be an important prerequisite for successful pregnancy.

The PI of the uterine arteries have been known to diminish progressively during the luteal phase Steer et al., [8], Goswamy et al., [9], Zaidi et al., [10] during which implantation occurs. Optimum uterine receptivity seems to occur when the mean pulsatility index of both arteries is between 2 and 3. Chang et al., [11] decreasing significantly the implantation and pregnancy rate when pulsatility is over 3 or 4, Bustillo et al., [12]. Tekay et al., [13] or when diastolic flow is not observed in the Doppler waveform Deichert et al., [14].

Similarly, Wang et al., [15] reported that 35\% of women who failed to conceive in IVF programme had a mean uterine artery PI value $>3.0$. Therefore, they suggested that embryo cryopreservation in those patients with a uterine artery PI $>2.99$ for transfer in subsequent cycles should be considered.

Some studies mentioned that a poor uterine perfusion might be one of the causes of unexplained infertility, Steer et al., [16] however, few studies correlate unexplained infertility and Doppler flow metry of the arteries responsible for uterine perfusion.

Inadequate blood flow would thus prevent implantation, although optimal uterine perfusion does not always mean pregnancy. In addition to this, high uterine resistance is observed in less than $10 \%$ of non-conception cycles, which suggests that this parameter is responsible for failure in implantation in very few cases Cacciatore et al., [17] .

A study done by Ziegler et al., [18] has suggested that low levels of progesterone might cause the uterine vascular impedance to increase. Therefore, using the secretory endometrium as an inclusion criterion in the present study was intended to 
determine (however indirectly) whether hormonal action was adequate in our group of women with unexplained infertility, and to ensure that the examination occurred during the luteal phase.

In conclusion, the presence of good uterine and endometrial blood flow is an important prerequisite for successful implantation and continuation of pregnancy as shown by higher uterine artery blood flow resistance. Those patients may have abnormalities in the uterine and endometrial blood flow. Despite these findings we could not find any cut off values that could predict the main cause of infertility in this group of which may be attributed to small sample size so larger prospective studies are needed aiming to confirm such results and reaching values that can accurately predict such cases.

\section{References}

1- HILL M.E., MOGHISSI K.S., MAGYAR D.M., HAYES M.F., ZADER J. and OLSON J.M .: Correlation of serum estradiol level and ultrasound monitoring to assess follicular maturation. Fertil. Steril., 46 (1): 42, 2005.

2- ISAKSSON R. and TIITINEN A.: Present concept of unexplained infertility. Gynecol. Endocrinol., 18: 278290, 2004.

3- STEER C.V., TAN S.L., MASON B.A. and CAMPBELL S.: Mid-luteal-phase vaginal Doppler assessment of uterine artery impedance in a sub-fertile population. Fertil. Steril., 61: 53-8, 1994.

4- GONG X., L1 Q., ZHANG Q. and ZHU G.: Predicting Endometrium Receptivity with parameters of spiral artery blood flow. Journal of Huazhong University of Science and Technology, 25: 335-8, 2005.

5. Y1LMAZ N., K1LiÇ S., MADENDAG Y., MADENDA$\mathrm{G}^{-} \mathrm{j}$, ÖZGÜN A, et al.: Endometrial parameters in IVF and IUI administration on elderly women. Turk. J. Med. Sci., 40: 343-8, 2010.

6- J.J. QIU, Y.L. LIU, M.H. LIU, L.P. CHEN, D.W. XU, Z.X. ZHANG, Q.C. YANG and H.B. LIU: Ovarian interstitial blood flow changes assessed by transvaginal colour Doppler sonography: predicting ovarian endometrioid induced injury to ovarian interstitial veesels. Arch. Gynecol. Obstet., 285 pp. 427-433, 2012.

7- BATTAGLIA C., LAROCCA E., LANZANI A., VALENTINI M. and GENAZZANI A.R.: Doppler ultrasound studies of the uterine arteries in spontaneous, IVF stimulated ovarian cycles. Gynecol. Endocrinol., 4: 245-50, 1990.

8- STEER C.V., CAMPBELL S., PAMPIGLIONE J.S., KINGSLAND C.R., MASON B.A. and COLLINS W.P.: Transvaginal color flow imaging of the uterine arteries during the ovarian and menstrual cycles. Hum. Reprod. 5: 391-395, 1990.

9- GOSWAMY R.K., WILLIAMS G. and STEPTO P.C.: Decreased uterine perfusion = a cause of infertility. Hum. Reprod., 3: 955-959, 1988.

10- ZAIDI J., PITTROF R., SHAKER A., KYEI-MENSAH A., et al.: Assessment of uterine artery blood flow on the day of human chorionic gonadotropin administration by Transvaginal color Doppler ultrasound in an in vitro fertilization program. Fert. Steril., 65: 37781, 1996.

11- CHANG Y.C., TSAI J.C., CHANG M.J., TAI F.T., KUNG L.C. and YANG S.Y.: Relationship of uterine perfusion to outcome of intrauterine insemi. J. Ultrasound. Med., pp. 633-636, 1996.

12- BUSTILLO M., KRYSA L.W. and COULAM C.B.: Uterine receptivity in an oocyte donation programme. Hum. Repord, 10 (2): 442/45, 1995.

13- TEKAY A., MARTIKAINEN H. and JOUPPILA P.: The clinical value of transvaginal colour Doppler ultrasound in assisted reproductive technology procedures. Hum. Reprod., 11: 1589-1591, 1996.

14- DEICHERT U., ALBRAND-THIELMAN C. and VAN de SANDT M.: Doppler sonographic pelvic blood flow measurements and their prognostic value in terms of luteal phase and implantation. Hum. Reprod., 11: 1591-1593, 1996.

15- L. WANG, L. QIAO, R. LI, X. ZHEN and Z. LIU.: The role of endometrial blood flow assessment with color Doppler energy in predicting pregnancy outcome in IVF/ET cycles Reprod. Biol. Endocrinol., 8: p. 122, 2010.

16- STEER C.V., TAN S.L. and DILLON D.: Vaginal color Doppler assessment of uterine artery impedance correlates with immuno-histochemical markers of endometrial receptivity required for the implantation of an embryo. Fertil. Steril., 63: 101-108, 1995.

17- CACCIATORE B., SIMBERG N. and FUSARO P.: Transvaginal Doppler study of uterine artery blood flow in invitro fertilization embryo transfer cycles. Fert. Steril., 66: 130-134, 1996 .

18- ZIEGLER D., BESSIS R. and FRYDMAN R.: Vascular resistance of uterine arteries: Physiological effects of estradiol and progesterone. Fertil. Steril., 55: 775-9, 1991. 


\section{دراسة الدوبلر للشريان الرحمى وشرايين المبايض بالدوبلر التصويرى

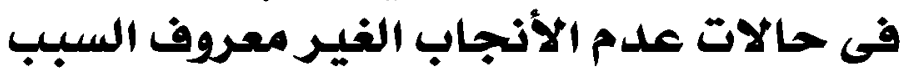

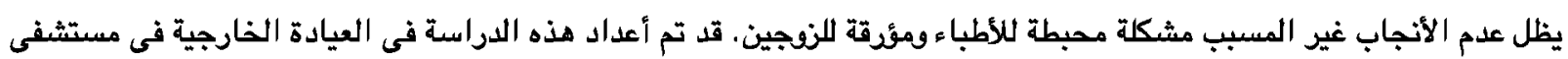

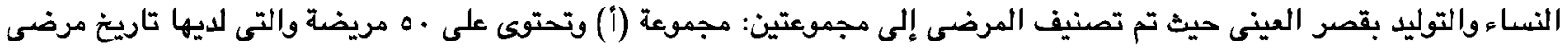

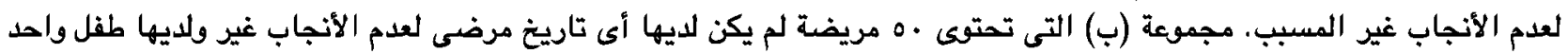

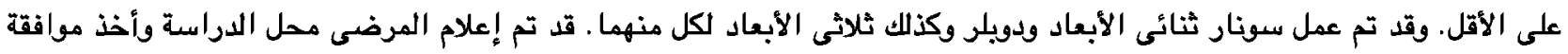

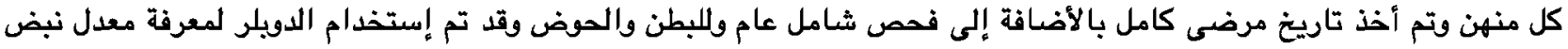

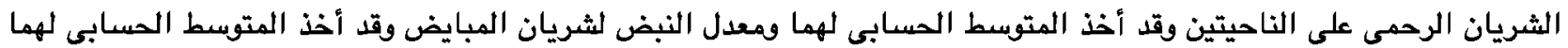
وقد حصلنا على النتائج الآتية:

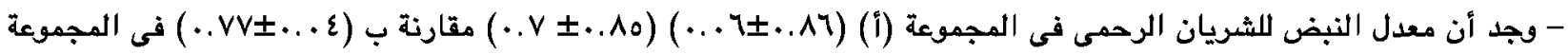

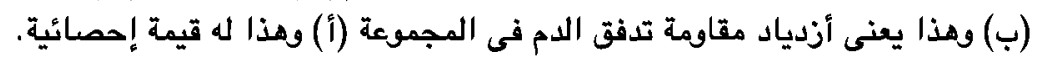

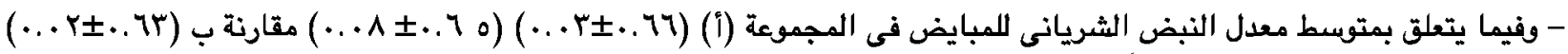

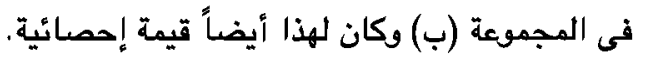

إذاً من رداستنا هذه تبين أنه من الممكن إفادة الحالات التى لديها التاريخ المرضى لعدم الأنجاب غير مسبب بتحسين تدفق الدم للرحم' من رداد 